\title{
The effects of dose of flupentixol decanoate on relapse rates in schizophrenia
}

\author{
Paul Reed, ${ }^{1}$ Tom Fanshawe ${ }^{2}$
}

The Psychiatrist (2011), 35, 293-296, doi: 10.1192/pb.bp.110.030916

${ }^{1}$ Royal Blackburn Hospital; ${ }^{2}$ Lancaster University

Correspondence to Paul Reed (paul.reed@lancashirecare.nhs.uk)

First received 22 Apr 2010, final revision 15 Nov 2010, accepted 7 Jan 2011

\begin{abstract}
Aims and method To systematically review the published literature with respect to formulating a dose-response curve for flupentixol decanoate. A systematic literature search using the Cochrane Database was performed for studies that published both dosage information and data on relapse rates.
\end{abstract}

Results The data showed modest effects of dose on survival rates. Increasing dose may be associated with increased survival rates up to around $50-60 \mathrm{mg}$ of flupentixol decanoate every 4 weeks. There was no evidence of increased survival rates at higher doses and higher doses may be associated with lower rates of survival. There is considerable uncertainty as to the true effects of dose of flupentixol decanoate on relapse rates.

Clinical implications There is no evidence that survival rates improve for doses above 50-60 mg every 4 weeks. These doses are much lower than doses commonly prescribed. Clinicians may wish to consider these data when prescribing flupentixol decanoate.

Declaration of interest None.
Antipsychotic medication is a mainstay in the treatment of schizophrenia. It is effective in treating symptoms and, when taken prophylactically, can prevent relapse. It is well established that many patients do not take their medication as prescribed, with adverse consequences including relapse. Some antipsychotic medications are available as long-acting depot injections and these preparations are thought to confer some benefit in terms of reduced relapse rates. Between a quarter and a third of patients with schizophrenia are prescribed such long-acting injections (LAI) and the rate is increasing. ${ }^{1,2}$ Despite this frequent prescription, the data on the use of LAI antipsychotics are scanty and much of the research on these preparations is old. ${ }^{3}$ There is also considerable uncertainty about optimal dosing. ${ }^{4}$ Recently there have been calls to improve the evidence base for prescribing LAI antipsychotics to promote a more appropriate use of these drugs. ${ }^{5}$

Flupentixol decanoate has a very wide dose range. For example, Taylor ${ }^{4}$ reports a dose range of $50 \mathrm{mg}$ every 4 weeks to $400 \mathrm{mg}$ every week. The maximal equivalent dose of flupentixol decanoate when compared with other depot conventional antipsychotics appears to be relatively much greater. There is uncertainty regarding whether such high doses confer benefit to the patient. Since surveys in the UK and New Zealand have suggested that flupentixol decanoate is the most commonly prescribed antipsychotic in these settings, it is perhaps a little surprising that it has not been more extensively researched. ${ }^{6,7}$

\section{Method}

The method of our review is based upon that of Taylor. ${ }^{8}$ The Cochrane library was searched for flupentixol decanoate. The Cochrane review for flupentixol decanoate ${ }^{9}$ was studied and supplemented by a MEDLINE search in December 2009. References were checked for additional studies.

Those papers which were randomised controlled trials in schizophrenia, specified dosage of flupentixol decanoate, contained relapse data and lasted 6 months or longer were included.

To indicate the relationship between flupentixol decanoate dose and survival rate, a Generalised Additive Model $^{10}$ (GAM) was fitted to the data obtained from the studies that met the inclusion criteria.

\section{Results}

Eight studies met all the inclusion criteria and all were included. The studies contained 12 different groups of patients prescribed flupentixol decanoate (Table 1).

The studies used a variety of designs and their duration varied from 24 weeks to 18 months. The selection of patients differed between studies. Four studies required their patients to have experienced a period of stability prior to entering the study. ${ }^{11,13,16,18}$

Only Kelly et $a l^{12}$ used fixed doses and studied consecutive out-patients. The sample in Cookson ${ }^{16}$ had 


\begin{tabular}{|c|c|c|c|c|}
\hline Study & Duration and sample & Dose & $\begin{array}{l}\text { Sample } \\
\text { size } \\
n\end{array}$ & $\begin{array}{l}\text { Survival } \\
\text { rate } \\
n(\%)\end{array}$ \\
\hline Agrup-Andersson et al ${ }^{11}$ & $\begin{array}{l}6 \text { months } \\
\text { Adherent female out-patients }\end{array}$ & $\begin{array}{l}\text { Mean } 40 \mathrm{mg} \text { every } 4 \text { weeks } \\
\text { (range } 10-30 \mathrm{mg})\end{array}$ & 28 & $22(79)$ \\
\hline Agrup-Andersson et al ${ }^{11}$ & $\begin{array}{l}6 \text { months } \\
\text { Adherent female out-patients }\end{array}$ & $\begin{array}{c}\text { Mean } 40.7 \mathrm{mg} \text { every } 2 \text { weeks } \\
\text { (range } 10-60 \mathrm{mg} \text { ) }\end{array}$ & 29 & $26(93)$ \\
\hline Kelly et $a l^{12}$ & $\begin{array}{l}9 \text { months } \\
\text { Consecutive out-patients with schizophrenia }\end{array}$ & 20 mg every 3 weeks & 15 & $12(80)$ \\
\hline Kelly et $a l^{12}$ & $\begin{array}{l}9 \text { months } \\
\text { Consecutive out-patients with schizophrenia }\end{array}$ & 40 mg every 3 weeks & 15 & $14(93)$ \\
\hline Pinto et $a l^{13}$ & $\begin{array}{l}18 \text { months } \\
\text { Stabilised out-patients with schizophrenia }\end{array}$ & $\begin{array}{l}\text { Mean } 36.6 \mathrm{mg} \text { every } 3 \text { weeks } \\
\text { (dose range not specified) }\end{array}$ & 31 & $29(94)$ \\
\hline Wistedt et $a l^{14}$ & $\begin{array}{l}24 \text { weeks } \\
\text { Out-patients with schizophrenia }\end{array}$ & $\begin{array}{l}\text { Mean } 27.5 \mathrm{mg} \text { every } 3 \text { weeks } \\
\text { (dose range not specified) }\end{array}$ & 8 & $5(63)$ \\
\hline Steinert et $a l^{15}$ & $\begin{array}{l}12 \text { months } \\
\text { Out-patients with schizophrenia }\end{array}$ & $40 \mathrm{mg}$ every 2 weeks & 16 & $12(75)$ \\
\hline Cookson $^{16}$ & $\begin{array}{l}44 \text { weeks } \\
\text { Patients with schizophrenia stabilised on high } \\
\text { doses for at least } 3 \text { months }\end{array}$ & Mean 333 mg every 2 weeks & 9 & $6(67)$ \\
\hline Cookson $^{16}$ & $\begin{array}{l}44 \text { weeks } \\
\text { Patients with schizophrenia stabilised on high } \\
\text { doses for at least } 3 \text { months }\end{array}$ & Mean $118 \mathrm{mg}$ every 2 weeks & 9 & $6(67)$ \\
\hline Johnson et $a l^{17}$ & $\begin{array}{l}12 \text { months } \\
\text { Out-patients with schizophrenia }\end{array}$ & $\begin{array}{l}\text { Mean } 9 \mathrm{mg} \text { per week } \\
\text { (range } 4-20 \mathrm{mg})\end{array}$ & 31 & $28(90)$ \\
\hline Johnson et $a l^{17}$ & $\begin{array}{l}12 \text { months } \\
\text { Out-patients with schizophrenia }\end{array}$ & $\begin{array}{l}\text { Mean } 6 \mathrm{mg} \text { per week } \\
\text { (range } 1.7-10 \mathrm{mg})\end{array}$ & 28 & $19(68)$ \\
\hline Lundin et $a l^{18}$ & $\begin{array}{l}1 \text { year } \\
\text { Out-patients with schizophrenia stable for } \\
3 \text { months }\end{array}$ & Mean $82 \mathrm{mg}$ per month & 28 & $-(53)^{b}$ \\
\hline
\end{tabular}

a. Studies which are listed twice contained two groups of patients, each receiving different doses or dose ranges of flupentixol decanoate. b. Only percentage rate given.

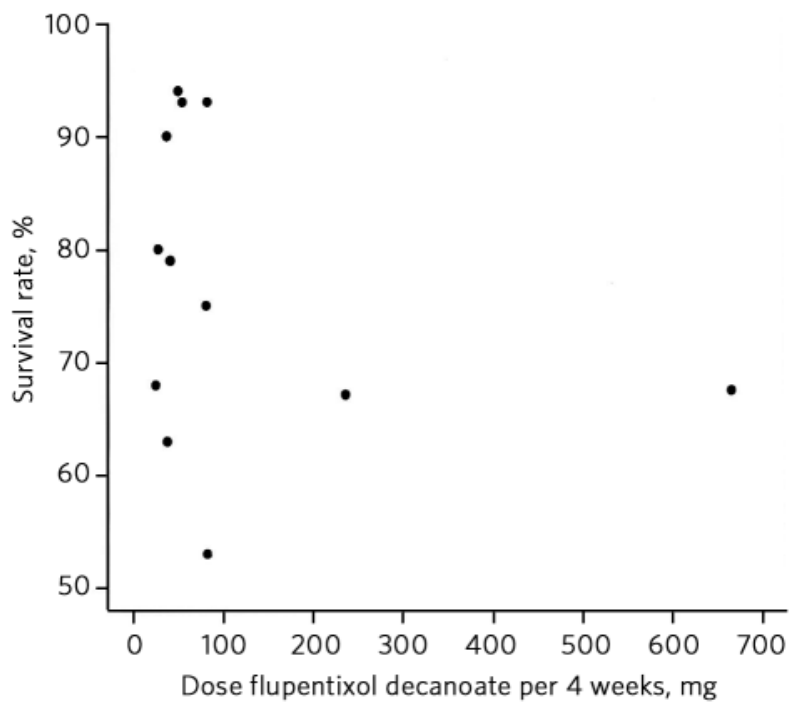

Fig 1 Survival rates by dose of flupentixol decanoate.

treatment-resistant schizophrenia. Therefore a degree of clinical heterogeneity is likely to be present.

The survival rates are shown in Fig. 1. Points are plotted at the average dose received by patients in each study. It can be seen (Table 1 and Fig. 1) that the two groups of patients from the Cookson ${ }^{16}$ study received much higher

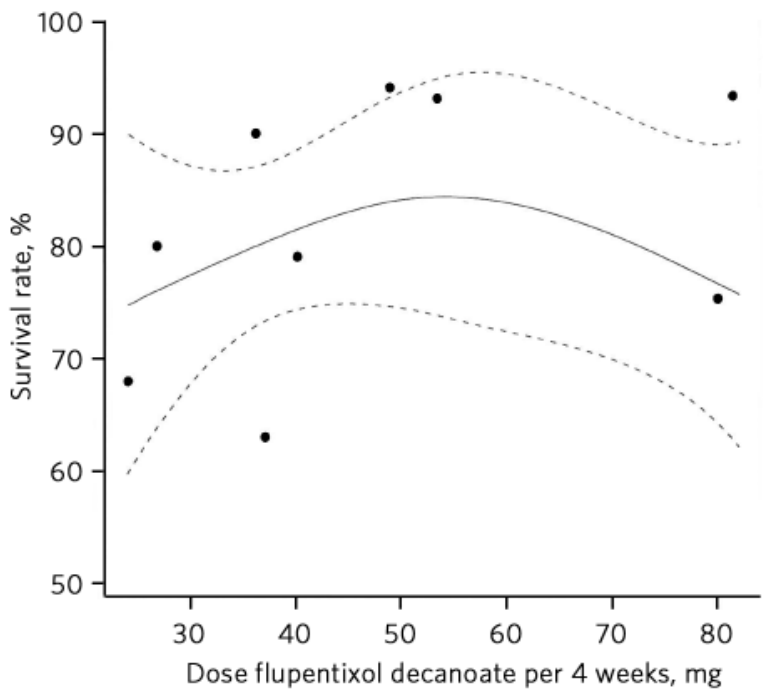

Fig 2 Survival rates by dose of flupentixol decanoate, excluding the Cookson study, with the best fitting curve from the Generalised Additive Model shown with 95\% confidence bands. Dotted lines represent the level of uncertainty.

doses than those in the remaining studies and appear to be outliers. In addition, these were patients with treatmentresistant schizophrenia who were unlikely to respond. These two groups were therefore excluded from further analysis. 
A dose-response curve was calculated for the remaining studies using the GAM method (Fig. 2). The level of uncertainty around the curve is shown by the dotted lines, which indicate two standard errors' difference from the fitted curve. The best-fit curve is a gently arcing curve with a peak between 50 and $60 \mathrm{mg}$. However, the slope of the curve is shallow, suggesting modest effect of dose on survival rate. In addition, the uncertainty of the true shape of the curve is substantial. Nonetheless, there is no clear suggestion that doses of flupentixol decanoate higher than 50-60 mg every 4 weeks confer additional benefit.

\section{Discussion}

The results shown here should be interpreted with caution for a number of reasons. First, the studies were generally small in terms of number of patients: 3 of the 12 groups studied comprised fewer than 10 patients and the largest group comprised only 31 patients. This raises questions of potential selection bias and how representative these samples are of the patient population at large. Also, the small numbers used make estimates of the survival rates in several of the studies relatively imprecise. Nonetheless, these studies represent the best available data for exploring the issue of the effects of flupentixol decanoate dose on survival in schizophrenia.

A further confounding factor is that some of these studies allowed for the concomitant use of rescue medication, which might also have affected the outcomes.

The reporting of the results, including definition of relapse, varies between the studies, which is also likely to have affected the outcomes.

The survival rates of over $90 \%$ in some of these studies are very high for schizophrenia. ${ }^{19}$ The three groups of patients with the highest survival rates (those in the AgrupAndersson et $a l,{ }^{11}$ Kelly et $a l^{12}$ and Pinto et $a l^{13}$ studies) all used doses of around $50 \mathrm{mg}$ flupentixol decanoate every 4 weeks. Interestingly, the sample from Pinto et al's study, ${ }^{13}$ as well as having the smallest relapse rate also had the longest follow-up. This suggests that flupentixol decanoate at modest dose can confer a good outcome for relatively long periods.

Johnson et $a l^{17}$ also achieved a high survival rate in a group of patients whose mean dose of flupentixol decanoate was $36 \mathrm{mg}$ every 4 weeks. The dose range in this group was $16-80 \mathrm{mg}$ every 4 weeks. This is a wide range, which largely obscures any specific effect of dose. It does, however, suggest that in some patients relapse does not occur with doses even lower than $50 \mathrm{mg}$ every 4 weeks. Certainly the patients in this group fared better than those in the comparison group who received a mean dose of $24 \mathrm{mg}$ flupentixol decanoate every 4 weeks and experienced more than 3 times the relapse rate $(32 \% v .10 \%)$. This is a statistically significant difference.

\section{Survival rates at higher doses}

Two of the studies reviewed (Steinert et $a l^{15}$ and Lundin et $a l^{18}$ ), like the Cookson ${ }^{16}$ samples, showed a poorer survival rate despite higher doses. The reasons for this are not clear. The two samples do not appear to have had treatment-resistant schizophrenia. Lundin et $a l^{18}$ used a relatively high mean dose of $82 \mathrm{mg}$ every 4 weeks. Also, the number of relapses in this study is reported only as a percentage rather than raw numbers. For this reason it is unclear as to whether this is an intention-to-treat analysis. Nine out of twenty-eight patients receiving flupentixol decanoate in this study were reported to have dropped out because of dissatisfaction with the prescribed medication, despite the investigators believing they had optimised dosage before study entry. The high drop-out rate suggests that tolerability was a problem in this study. The use of mean (rather than fixed) doses may again have obscured a true dose effect in this study.

The maximal survival rate at around 50-60 mg every 4 weeks is in marked contrast to the licensed ${ }^{20}$ maximal dose of $400 \mathrm{mg}$ every week (equivalent to $1600 \mathrm{mg}$ every 4 weeks) for flupentixol decanoate. It is also towards the lower end of the range recommended by other research and guidelines. ${ }^{4,21,22}$

Reports of actual dosage prescribed are even higher. For example, Taylor ${ }^{4}$ reports a typical dose of flupentixol decanoate of $60 \mathrm{mg}$ every 2 weeks, whereas in a large UK survey, Barnes et $a l^{2}$ found an even higher median dose of $50 \mathrm{mg}$ every week. These doses are considerably higher than the dose at which our curve peaked.

It is of course possible that increasing dose may confer a poorer outcome. The data presented here cannot confirm or refute this. Poorer response rates at higher doses have been suggested in other studies of conventional antipsychotics. $^{23}$

\section{Survival rates at lower doses}

The situation for lower doses is also uncertain. The shape of the curve is compatible with increased relapse rates with lower dosage. However, the results are conflicting, with the Johnson et $a l^{17}$ study showing good survival at a mean dose of $36 \mathrm{mg}$ every 4 weeks, whereas Wistedt et $a l^{14}$ found a much higher relapse rate at a similar (mean $33 \mathrm{mg}$ every 4 weeks) dosage. Kelly et $a l^{12}$ found a good survival rate in their patients with a fixed dose of $20 \mathrm{mg}$ every 3 weeks. Given that they also studied consecutive out-patients, the risk of selection bias might be lower in this study and the results more reliable.

The lowest effective dose in our review is $20 \mathrm{mg}$ flupentixol decanoate every 3 weeks, with an impressive survival rate of $80 \% .{ }^{12}$ The one group of patients where the mean dose was lower was the low-dose group in the Johnson et $a l^{17}$ study (average $18 \mathrm{mg}$ every 3 weeks). As some of these patients would have received much less than the $20 \mathrm{mg}$ every 3 weeks received in the Kelly et $a l^{12}$ study, this might explain the worse outcome. Agrup-Andersson et $a l^{11}$ also found higher relapse rates in their lower-dose group (mean $21.4 \mathrm{mg}$ every 4 weeks), although this was not statistically significant.

All this suggests that doses lower than $20 \mathrm{mg}$ every 3 weeks are likely to be too low for most patients.

Studies of other depot antipsychotic drugs using similar methods have also indicated maximal survival rates at modest dosage. Taylor ${ }^{8}$ estimated a near-maximal response to haloperidol decanoate at $100 \mathrm{mg}$ every 4 weeks. Davis \& Chen $^{24}$ estimated that the near-maximal effect of 
fluphenazine decanoate was achieved at a dose of $25 \mathrm{mg}$ every 4 weeks. Neither study, however, suggested reduced benefits with higher doses. Using the British National Formulary dose equivalence table, ${ }^{20}$ the dose equivalents of flupentixol decanoate from the Taylor study is $80 \mathrm{mg}$ every 4 weeks and for the Davis \& Chen study it is $40 \mathrm{mg}$ every 4 weeks.

Overall, it would be unwise to draw too many conclusions from the data presented here because of the heterogeneity between studies, the small samples and the uncertainty around the true shape of the curve. Also, the data represent the outcomes of groups of patients rather than individuals, whereas the effect of dose is likely to vary between individual patients. The data presented here cannot determine the dose requirement of an individual patient. On the other hand, the data offer no support for increased benefit above doses of 50-60 mg every 4 weeks. Data also suggest that it is likely that lower doses may be effective for some patients.

\section{About the authors}

Paul Reed is a consultant psychiatrist at the Royal Blackburn Hospital, Blackburn, Lancashire, and Tom Fanshawe is a lecturer in medical statistics at the School of Health and Medicine, Lancaster University.

\section{References}

1 Burns T. Knowledge about antipsychotic long-acting injections: bridging that gap. Br J Psychiatry 2009; 195 (suppl 52): s5-6.

2 Barnes TRE, Shingleton-Smith A, Paton C. Antipsychotic long-acting injections: prescribing practice in the UK. Br J Psychiatry 2009; 195 (suppl 52): s37-42.

3 Adams CE, Fenton MKP, Quraishi S, David AS. Systematic meta-review of depot antipsychotic drugs for people with schizophrenia. $\mathrm{Br} J$ Psychiatry 2001; 179: 290-9.

4 Taylor D. Psychopharmacology and adverse effects of antipsychotic long-acting injections: a review. Br J Psychiatry 2009; 195 (suppl 52): s13-9.

5 Patel MX, Taylor M, David AS. Antipsychotic long-acting injections: mind the gap. Br J Psychiatry 2009; 195 (suppl 52): s1-4.

6 Paton C, Lelliott P, Harrington M, Okocha C, Sensky T, Duffett R. Patterns of antipsychotic and anticholinergic prescribing for hospital inpatients. J Psychopharmacol 2003; 17: 223-9.

7 Humberstone V, Wheeler A, Lambert T. An audit of outpatient antipsychotic usage in the three health sectors of Auckland, New Zealand. Aust N Z J Psychiatry 2004; 38: 240-5.
8 Taylor D. Establishing a dose-response relationship for haloperidol decanoate. Psychiatr Bull 2005; 29: 104-7.

9 David A, Adams CE, Quraishi SN. Depot flupenthixol decanoate for schizophrenia or other similar psychotic disorders. Cochrane Database Syst Rev 1999; 2: CD001470.

10 Wood SN. Generalized Additive Models: An Introduction with R. Chapman and Hall/CRC, 2006.

11 Agrup-Andersson L, Bengtsson A, Erlandsson K, Gottfries CG, WitzellOstlund G. Flupenthixol decanoate: controlled investigation concerning dosage. Acta Psychiatr Scand 1974; 255 (suppl): 7-14.

12 Kelly HB, Freeman HL, Banning B, Schiff AA. Clinical and social comparison of fluphenazine decanoate and flupenthixol decanoate in the community maintenance therapy of schizophrenia. Int Pharmacopsychiatry 1977; 12: 54-64.

13 Pinto R, Banerjee A, Ghosh N. A double-blind comparison of flupenthixol decanoate and fluphenazine decanoate in the treatment of chronic schizophrenia. Acta Psychiatr Scand 1979; 60: 313-22.

14 Wistedt B, Jorgensen A, Wiles D. A depot withdrawal study: plasma concentration of fluphenazine and flupenthixol and relapse frequency. Psychopharmacology 1982; 78: 301-4.

15 Steinert J, Erba E, Pugh CR, Robinson C, Preist RG. A comparative trial of depot pipothiazine. J Int Med Res 1986; 14: 72-7.

16 Cookson IB. The effects of a $50 \%$ reduction of $\operatorname{cis}(Z)$-flupenthixo decanoate in chronic schizophrenic patients maintained on a high dose regime. Int Clin Psychopharmacol 1987; 2: 141-9.

17 Johnson DA, Ludlow JM, Street K, Taylor RD. Double-blind comparison of half-dose and standard-dose flupenthixol decanoate in the maintenance treatment of stabilised out-patients with schizophrenia. Br J Psychiatry 1987; 151: 634-8.

18 Lundin L, Dencker SJ, Malm U. Community-based rehabilitation of schizophrenia. Nord Psykiatr Tidsskr 1990; 44: 81-7.

19 Leucht S, Barnes TRE, Kissling W, Engel RR, Correll C, Kane JM. Relapse prevention in schizophrenia with new-generation antipsychotics: a systematic review and exploratory meta-analysis of randomized controlled trials. Am J Psychiatry 2003; 160: 1209-22.

20 BMJ Group, Royal Pharmaceutical Society of Great Britain. British National Formulary 60. BMJ Group \& Pharmaceutical Press, 2010.

21 Taylor D, Paton C, Kapur S. The Maudsley Prescribing Guidelines (10th edn). Informa Healthcare, 2010.

22 Gardner DM, Andrea L, Murphy AL, O'Donnell H, Centorrino F, Ross J, et al. International Consensus Study of Antipsychotic Dosing. Am J Psychiatry 2010; 167: 686-93.

23 Geddes J, Freemantle N, Harrison P, Bebbington P. Atypical antipsychotics in the treatment of schizophrenia: systematic overview and meta-regression analysis. BMJ 2000; 321: 1371-6.

24 Davis JM, Chen N. Dose response and dose equivalence of antipsychotics. J Clin Psychopharmacol 2004; 24: 192-208. 